\title{
The Impact of Community-Based Physical Activity Projects on Girls' and Young Women's Engagement in Physical Activity: Findings from an Evaluation of the 'Girls on the Move' Programme
}

\author{
John Taylor and Adrienne Hughes \\ School of Sport, University of Stirling, Stirling, FK9 4LA, UK
}

\author{
Pelagia Koufaki \\ School of Life Sciences, Heriot-Watt University, Edinburgh, EH14 4AS, UK
}

\begin{abstract}
Using findings of an evaluation of the 'Girls on the Move' Programme in Scotland, this paper assesses the short-term (up to 6-months) impact community-based projects can have on girls' engagement in physical activity. Attendance, drop-out, frequency, duration and intensity of participation in physical activity are considered. The findings indicate that around six-out-often girls maintained their involvement in the projects and that four-out-of-ten girls had high levels of attendance. Although the amount of time spent in moderate to vigorous physical activity (MVPA) was low (average of 10 minutes per hour of activity), the findings suggest that girls' activity increased between the beginning and end of projects but remained below healthy reference values. While short-term community-based projects can contribute to daily activity, organised activity sessions need to be supplemented with other forms of physical activity (e.g. PE, active living) if girls are to attain the recommended 60 minutes of MVPA per day.
\end{abstract}

Keywords: physical activity, participation, girls

\section{INTRODUCTION}

The importance of physical activity to health is now well established. Those that have physically active lifestyles are less likely to suffer from chronic diseases such as obesity, 
diabetes, cardiovascular disease, cancer, osteoporosis, depression and hypertension. Furthermore, those that are physically active have longer life expectancies than those who are inactive or sedentary (Warburton, Nicol and Bredin, 2006). Despite the protective health benefits of physical activity, many children and adults are inactive, with evidence showing that females are likely to be less active than males. Research in Scotland has shown that female participation in physical activity is lower than males at all ages, and for girls, the decline in levels of physical activity is most pronounced between the ages 10-11 and 14-15 (see Figure 1) (Scottish Executive, 2003). At age 10-11, two-thirds (66\%) of girls take part in the recommended levels of physical activity (60 minutes of moderate to vigorous physical activity (MVPA) most days of the week), but by age 14-15 this has dropped to a little over one-third (35\%).

\section{INSERT FIGURE 1}

A number of factors are thought to contribute to the decline in levels of activity at these ages. Many girls and young women dislike competitive sport and physical education (Dwyer et al, 2006; Sleap and Wormald, 2001; Vu, et al, 2006), some feel that being active can conflict with girls' perceptions of their femininity, it can create fears about looking stupid, there is a perceived lack of choice, and it can raise fears about their personal safety (Dwyer et al, 2006; EPPI, 2001; sportscotland, 2005). In addition, there are other practical barriers to participating such as access to facilities and equipment, cost implications and transport issues, although these barriers are not confined to girls and young women (Dwyer, 2006; sportscotland, 2005). Furthermore, a number of different communities have been identified as having lower levels of participation than the population as a whole, including those from socially and economically deprived areas, those from ethnic minority groups, young mums and those with disabilities (Sport England, 2002; sportscotland, 2005). 
As a means of addressing some of these issues in Scotland, a number of national initiatives have been introduced to increase participation in young people more generally (e.g. Active Schools) and girls in particular (Fit for Girls, YDance and 'Girls on the Move' Programme), aimed at contributing to Scottish government's strategic goal to "increase and maintain the proportion of physically active people in Scotland" (Scottish Executive, 2003, p22).

\section{The 'Girls on the Move' Programme}

The 'Girls on the Move' Programme is a community-based physical activity intervention established through a partnership between The Robertson Trust and the Scottish Executive (now known as The Scottish Government). The programme, which was launched in 2005, was established (in part) in response to the 1998 Scottish Health Survey data (see Figure 1) and was aimed at increasing the physical activity levels of girls and young women aged 1118 by addressing the barriers that prevent them from participating in activity (including cost, availability, access, male dominated culture and ethnicity) (sportscotland, 2005). The primary target group were sedentary or inactive girls from socially deprived backgrounds. It aimed to give girls and young women opportunities and choices to achieve social, psychological and physical benefits possible through physical activity. Although funded initially for a period of three years with a programme budget of $£ 450,000$, The Robertson Trust and the Scottish Government committed funding for a further three years from 2008.

The 'Girls on the Move' Programme has two distinct programmes:

(i) The Participation Programme, which provides grants of up to $£ 5,000$ (although this was reduced to $£ 2,000$ after Year 2 of the programme) to voluntary and community groups to fund projects which are aimed at increasing physical activity levels among girls and young women, increase girls' enjoyment of physical activity and raise awareness of the benefits of a healthy lifestyle. 
(ii) The Leadership Programme, which provides leadership training courses for young women aged 16-25 to allow them to increase opportunities for girls to take part in organised physical activities in their local communities.

This paper focuses on the findings obtained through the Participation Programme.

\section{The Participation Programme Projects}

Over the first five years, 154 projects received Participation Programme awards ranging from $£ 500$ up to $£ 5,000$ with the average award amounting to $£ 2,042$. These awards were used by community groups to cover the cost of delivering physical activity projects to girls including: hall hire; fees for coaches/ instructors/teachers; transport; and equipment where necessary. Five broad types of physical activity were delivered at projects, with most delivering more than one type, these were: (i) dance activities which were delivered at $65 \%$ of projects (inc. street dance, hip-hop, jazz, Asian), (ii) health and fitness activities at $51 \%$ of projects (inc. aerobics, boxercise, Pilates, yoga), (iii) outdoor activities at $28 \%$ of projects (inc. canoeing, gorge walking, horse-riding, mountain biking, skiing/snowboarding), (iv) sports at $25 \%$ of projects (inc. badminton, basketball, football, rugby), and (v) other at $15 \%$ of projects (inc. motocross, ice skating, ten-pin bowling, martial arts/self-defence). The projects lasted from one week (five consecutive days) up to six months of weekly sessions with a mean average of 21 girls attending projects. Most sessions were one to two hour long although some of the outdoor activities lasted a full day, some of which were part of a residential experience.

The scope of the projects was extensive and included projects in inner-city and rural locations across Scotland including the western and northern isles, and included projects targeted at girls from ethnic minority groups, young mums, and girls with disabilities. The 
programme was successful in reaching girls from more deprived areas with 34 per cent of girls coming from the 20 per cent of most deprived areas across Scotland (based on analysis of postcodes and assessment against Scottish Index of Multiple Deprivation (SIMD) data). Furthermore, 14 per cent of girls were from minority ethnic groups (which is substantially higher than the $2 \%$ of the Scottish population that are from BME groups (Scottish Executive, 2004)), and four per cent of participants were mums which, based on their ages, was roughly representative of young mums in Scotland.

A challenge faced in evaluating the programme was the diverse nature of the projects funded. They differed in: the number of participating girls; the age ranges of the girls (from 11 up to 18); the range of activities; the geographic locations; and the types of deliverers (e.g. coaches, teachers, instructors, youth workers, young leaders). There were only two aspects of projects that needed to be the same (i) they all had 'girls only' status - no boys were permitted to take part - this was to address the often dominating attitude of boys in physical activity and sports contexts (sportscotland, 2005); and, (ii) girls must have been be involved in the design of the project - the Programme was designed to be demand, rather than supply, led. As a result, the most commonly requested and delivered activities were dance related, albeit in a variety of styles.

\section{EVALUATION APPROACH}

The original brief for the evaluation requested that a broad range of data were collected to establish progress on delivery of the programme (process evaluation) and achievement of outcomes (outcome evaluation). Although the evaluation sought evidence on a broad range of outcomes, this paper focuses on the findings associated with girls' levels of physical activity. A range of quantitative and qualitative methods were used in the evaluation to assess the extent of a broad range of outcomes. Using self-reporting and objective 
measures of physical activity, this paper assesses what impact short-term community-based activity projects had on girls' participation in physical activity. The findings in this paper have been drawn primarily from data collected by project organisers using the Project Monitoring and Reporting Toolkit and data collected during visits to projects.

\section{Project Monitoring and Reporting Toolkit}

The main approach to collecting data from the groups funded through the Participation Programme was the Project Monitoring and Reporting Toolkit, a resource designed for the programme that was adapted and amended as the Programme developed. Each participating group was sent a presentation ring binder that contained a number of monitoring tools. Data obtained using three of the data collection tools are presented in this paper: (i) attendance sheets; (ii) pre- and post-project questionnaires for the participants; and (iii) preand post-project physical fitness profile forms to gather data on girls' health related fitness. Organisers at each project were provided training on how to collect the data and were asked to collect the data as the project progressed and return the completed materials after the project was completed. In total, 96 out if the 154 projects (62\%) returned at least one element of the evaluation toolkit, although few returned all the information requested.

Monitoring Attendance at 'Girls on the Move' Projects

In order to establish the level of attendance, Project Attendance Sheet (see Figure 2) requested details on each girl that attended the project and which sessions they attended. The forms were used to assess: the total number of participants; the proportion of girls staying involved; the proportion of girls dropping out; and to help assess total throughput at each project.

\section{Insert Figure 2}


Keeping attendance in some contexts is not usually well liked by group leaders or participants because it takes time and the data are often not used (Wheeler et al, 2006). Through discussions with project organisers at the beginning of the programme, it was clear that keeping attendance was not a common activity. It was considered to be administratively inconvenient, but also unnecessary, which indicates that systematic analysis of the impact of these voluntary and community groups based on attendance does not usually take place. Although attendance records were not usually kept at participating groups, 45 per cent of organisers returned completed attendance sheets. This provided details on the attendance patterns of 1,470 girls. The mean average number of girls at these projects was 21 (ranging from 5 girls up to 171 girls - SD=23.0), with projects delivering on average 18 sessions (ranging from 4 sessions up to 63 sessions - $S D=12.7$ ).

\section{Pre-project and Post-project Surveys of Girls - IPAQ Survey}

The pre-project and post-project surveys gathered data on a range of issues including: participation in activity; enjoyment of activity; physical self-description; age; disability, ethnicity; school/employment status; and through postcode analysis, socio-economic profile. This paper presents findings obtained from the IPAQ (short version) questionnaire which was introduced in Years 4 and 5 of the Programme.

Self reported levels of physical activity and sedentary behaviour were determined via the use of the International Physical Activity Questionnaire (IPAQ-short version) (available from: www.ipaq.ki.se). This questionnaire has been validated in adults from 15-69 years of age, but to ensure the accurate completion of the questionnaires, we requested that project organisers and deliverers assisted younger girls in completing the questionnaires at the beginning and end of the projects. Specialised training and practice trials were provided during the Toolkit Training Days. 
The IPAQ-short, asks about frequency and duration of perceived vigorous and moderate intensity physical activities performed during the last 7 days. Two additional questions on frequency and duration of walking and sitting time accumulated over the last 7 days are also included in the short form questionnaire. Data from the IPAQ questionnaires were processed, scored and analysed according to published recommendations available from: http://www.ipaq.ki.se/ipaq.htm.

For the purposes of this paper only data from matched pre-post questionnaires $(n=88)$ are presented. The number of post-project questionnaires was substantially less than the preproject questionnaires, suggesting that many participants had either dropped out by the time the project ended or did not complete/return the post-project evaluation materials. For the purposes of this analysis, only girls aged 12 and over (those in secondary school or beyond) were included - this provides a clear analysis of the impact of projects on the main target age group. Pre-post project comparisons were performed using the Wilcoxon Signed Ranked Tests and significance levels was set at $p<0.05$.

\section{Pre-project and Post-project Physical Fitness Profiles}

As part of the evaluation process, data were collected to determine the health related physical fitness characteristics of girls and whether the funded projects delivered physical activity sessions at a level which could induce minimum noticeable changes in health related physical function markers. Given that the majority of funded projects proposed physical activity sessions over a course of several weeks, this provided an ideal setting for evaluating real life community-based and delivered physical activity interventions in young girls' health related fitness indices. For this purpose, a battery of simple, widely used performance based tests, were introduced in order to develop a physical fitness profile for each girl including: 1 mile walk/jog; sit ups; push ups; sit-to-stand; and sit and reach. 
Although, it is understood that the primary aim of the Programme was not to deliver exercise training programmes for enhancing physical performance, it was decided to introduce this physical fitness profiling tool, not only as a monitoring tool for evaluation purposes, but also as a self motivational, educational and monitoring tool for girls to use beyond their involvement in the projects. Instructions and illustrations on how to use this step of the evaluation process were detailed in the toolkit folder. This step was also extensively addressed, explained and demonstrated at training sessions with project organisers (but not all organisers attended training sessions). All the physical performance tests were validated and widely used in the paediatric population with normal scores established for girls in all age ranges (Barker et al, 2001; Committee for the Development of Sport (CDDS), 1988; Institute for Aerobics Research, 1987). For this part of the evaluation, the recommendations were that girls would work in pairs, under the guidance and supervision of the deliverer or organiser to develop their individual profiles at the beginning and end of the projects.

\section{Measuring Intensity of Activity - Accelerometer Data}

Observations at visits to projects in the first three years of the Programme and reviews of DVDs supplied by project organisers revealed that girls' levels of activity at projects varied extensively - some girls appeared very active in sessions but others appeared to be very lethargic. These observations raised issues about how active girls were when taking part in funded projects. In order to assess moderate to vigorous levels of physical activity (MVPA), visits were made to 13 projects where ActiGraph uniaxial accelerometers were used to obtain objective measures of the girls' levels of physical activity. The accelerometers were small, match-box sized devices that were worn by the girls on a belt that fitted around their waist. The accelerometers recorded the girls' movement and the data were used to assess activity at sedentary, light intensity, moderate and vigorous levels. The devices were set to record movement in 15 second epochs which matches previous studies (Hughes, 
Henderson, Ortiz-Rodriguez, Artinou and Reilly, 2006). This epoch was chosen to provide optimal recording of moderate and vigorous intensity levels, as young people's activity tends to be sporadic and in short bursts (Nilsson, Ekelund, Yngve and Sjöström, 2002). The activities chosen were identified as suitable for measurement using accelerometers. Data were obtained from 77 girls providing insight into the levels of activities obtained by girls at typical 'Girls on the Move' projects.

\section{Self-Selection Bias}

It is important to recognise that some of the data from the evaluation was affected by selfselection bias and a reluctance of some organisers and leaders to collect data, particularly so for the data relating to physical fitness profiles. At the Toolkit Training Days it was clear that some organisers and leaders were reluctant to administer some of the 'fitness tests' because they felt the girls would not want to take part. Some leaders also suggested that the girls were reluctant to take part in the tests. Consequently, the sample sizes for some of the tests were small and the findings may be more indicative of girls with higher physical selfawareness. However, these issues highlight some of the methodological problems associated with measuring impacts at community-based projects.

\section{ATTENDANCE AT 'GIRLS ON THE MOVE’ PROJECTS}

Girls' attendance varied markedly across projects. Some recorded high levels of attendance with most sessions being full each week, while some struggled to attract and retain girls. It was estimated that attendance across all projects was 66 per cent - that is two-thirds of the total possible throughput for all sessions delivered (number of sessions delivered multiplied by the number of places available) were filled. One project filled only 20 per cent of the places available, although the project organiser was not able to explain why attendance was so low. 


\section{Insert Table 1}

Some project organisers reported having to increase the number of sessions or increase the number of places due to the demand generated by the project. Twenty projects delivered more than the planned number of sessions (primarily due to an under-spend on the project budget, therefore having sufficient funds to deliver more), while 17 projects delivered fewer sessions than anticipated (due to problems in attracting enough girls to participate, absence of instructors/teachers, unavailability of facilities). Unfortunately the data are not sophisticated enough to explain reasons why such differences occurred, although well planned and delivered sessions were considered critical by project organisers.

\section{Girls' Frequency of Participation at Projects}

In total, 61 per cent of all the girls that attended the projects were involved at the end, with 39 per cent identified as having dropped out of the project activities. In terms of full adherence to the projects less than one-in-five girls (18\%) attended all the sessions at their projects.

The attendance sheets were used to identify the proportion of girls with low, moderate and high levels of attendance. They showed that 40 per cent of the girls had a high level of attendance (i.e. they took part in more than three-quarters of the sessions delivered at their projects). Less than one quarter (23\%) of girls had moderate levels of attendance, while 37 per cent had low (16\%) or very low $(21 \%)$ levels of attendance (i.e. they attended only a small number of sessions and typically dropped out of the project before it finished).

\section{Insert Table 2}


Many of those with very low levels of attendance attended only one session before dropping out, with others attending only two or three before leaving.

\section{Drop Out}

It is inevitable that some participants will drop out of the activities. The attendance sheets suggest that around 39 per cent of girls engaged in the Participation Programme dropped out - that is, they did not take part in either of the last two sessions. This figure probably represents an over estimate as some of these girls may still have been active in projects but were unable to attend the final sessions (e.g. other commitments, illness). Analysis of beginning of project survey data from girls that did not subsequently complete an end of project questionnaire (an assumption being that many of these will be girls that dropped out of the projects) show few differences between those that stayed involved and those that dropped out. However, those that dropped out were generally more active before the project than those that stayed $(35 \%$ of drop outs were active on 5 or more occasions in the week prior to the project starting compared to $26 \%$ of those that stayed - not statistically significant) and were from more affluent areas (6\% of drop outs were from the most deprived areas compared to $31 \%$ of those that stayed - statistically significant $p<0.05)$. This could be explained by those from more affluent backgrounds having greater choice in the activities they can do.

Most organisers (although not all) were aware of the likely reasons for drop out. They identified issues with the content of activity programmes (e.g. the activity was not liked; a lack of variance to weekly routines), group dynamics (e.g. cultural differences; problems with bullying) and individual issues affecting girls (e.g. lack of motivation and commitment; lack of self-confidence; overweight). Some organisers explained that the "the chaotic nature" of the lives of some of the girls resulted in some girls having to drop out. For example, "one girl had a baby" and "one girl experienced temporary homelessness". Girls' lack of confidence 
was also highlighted as an issue affecting involvement by several groups, which required deliverers to provide lots of encouragement to help maintain some girls' involvement.

\section{INTENSITY OF PARTICIPATION IN SELECTED ACTIVITIES}

From observations taken at the visits and reviewing DVDs of the girls involved in project activities, it was evident that the intensity of girls' physical activity varied considerably. For example, in some dance sessions reviewed, it was clear that some girls were very active, with the dance moves being performed in a very energetic and dynamic way, while for others in the same session, some appeared to be quite inactive. In Years 4 and 5 of the Programme, data were collected from 13 projects using accelerometers to assess the intensity of activity in which the girls were engaged.

The findings from the accelerometers show that the average amount of time spent by girls at moderate to vigorous physical activity (MVPA) levels over a period of one hour was 10 minutes (or 17\%), with some activities recording higher MVPA than others. Although 'sports' activities were less in demand for the girls, the accelerometer data showed that the amount of MVPA at two sports' projects (rugby and basketball) were higher compared to the other activities. Just under one-third (30\%) of the basketball session and around one-quarter $(26 \%)$ of the rugby sessions was spent in MVPA. While dance was by far the most common type of activity available through the Participation Programme, it was the dance projects that generated the lowest amounts of MVPA. Overall, only eight per cent of the time spent at the dance projects was in MVPA, an average of five minutes for every hour of activity.

With most sessions at project lasting about one hour at a time, the amount of time girls spent in MVPA was around one sixth of the recommended 60 minutes of moderate to vigorous physical activity recommended for children. 


\section{Insert Table 3}

Of some concern to stakeholders were the high levels of sedentary behaviour. Girls spent over one-half $(55 \%)$ of the time at the projects being inactive. Sedentary behaviour was particularly noticeable at some of the dance projects where more than three-quarters of the time was spent being inactive. The nature of dance activity, particularly for beginners, can be quite sedentary. When learning how to dance much of the time is spent watching the teacher, and then slowly mimicking the moves before performing the dance. It is worth noting, especially with regard to the dance projects, that the longer the project runs (i.e. number of weeks), a greater the amount of MVPA is generated. The dance project that generated the highest levels of MVPA (19\%) had been running for 10 weeks, while the three projects with the lowest levels of MVPA had been running for the shortest amounts of time. This can most likely be explained by the participants improving their knowledge of the dances being performed, resulting in less time spent watching or copying the teacher.

Although dance activity generated lower levels of activity than other types of activity, dance was the preferred choice of activity for most girls. Although offering more sport options might be regarded as an approach to increasing activity, the clear message from girls was that sport was not as desirable. It should also be recognised that despite the generally low levels of activity, getting the girls to engage in light intensity physical activity is better than no activity. While engaging in activity, people are less likely to be engaged in other health harming activities like snacking. Consequently, if the activity displaces previously unhealthy activities, the light increases in activities could be considered important to improving health.

\section{THE IMPACT OF PROJECTS ON GIRLS' LEVELS OF PHYSICAL ACTIVITY}

In terms of understanding the impact of the projects on increasing girls' physical activity, Table 4 below compares the pre- and post-project survey results for the girls that returned 
both a pre-project and a post-project IPAQ questionnaire. The number of matched pre-post questionnaires $(n=88)$ was substantially less than the number of baseline IPAQ questionnaires returned, suggesting that many participants had either dropped out by the time the project ended or did not complete/return the post project evaluation materials.

For the purposes of this analysis, only girls aged 12 and over (mean $14.7 \pm 2.29$ ) (those in secondary school or beyond) were included - this provides a clear analysis of the impact of projects on the main target age group for the 'Girls on the Move' Programme.

The results indicate that self-reported habitual levels of physical activity significantly improved during involvement in the projects. Even though results are based on a small percentage of the whole sample size, what seems to be quite encouraging is that even involvement in short-term physical activity promotion programme such as 'Girls on the Move' (10-30 hours of contact per person over 2-6 months), can produce favourable improvements for some girls.

The number of days per week and the number of minutes per day spent in vigorous and moderate activity increased between the beginning of the projects and the end of the projects. Despite these increases there were some discrepancies between the IPAQ survey data and the accelerometer data, particularly where vigorous intensity activity is concerned. The survey findings suggest that the mean number of days per week spent taking part in vigorous activity increased from 1.73 days to 2.48 days, with the number of minutes per day increasing from 52.10 minutes to 68.90 minutes. However, the accelerometer studies showed that the girls took part in little to no vigorous activity during the 'Girls on the Move' sessions. Previous studies have shown that self-reported measures of activity are often exaggerated and the findings here would suggest this was the case here - unless of course the girls get their vigorous activity in other contexts, but this is considered unlikely. However, 
despite the possible over estimation in the amount of time spent in MVPA, the reported increases may suggest that the participants have become more active.

\section{Insert Table 4}

Matching the increase in activity, there was a decline in the amount of time spent sitting. Girls suggest that the mean amount of time spent sitting per day declined by around 66 minutes between the beginning and end of the project.

The number of girls that reported at least 6 days of moderate intensity exercise and at least 3 days of vigorous intensity exercise increased from two at baseline, to 16 at the end of projects. Although the numbers are small this represents a positive change in the reported physical activity levels of girls.

\section{Health Related Fitness Indicators}

The results of health related fitness indicators on endurance, strength and flexibility were limited due to the low number of responses. The introduction and completion of the health related fitness profile faced a significant amount of resistance from project organisers (predominantly youth workers). As a result, completed and returned data were substantially less as a percentage of all possible returns. Anecdotally, the main reasons behind an obvious resistance towards implementing an evaluation task that involved physical assessment were:

- Concerns about promoting negative feelings among the girls, especially if some girls performed less well compared to other girls in the group; 
- Concerns about promoting a "competitive" feeling among the girls, a feeling that that was perceived as negative; and

- A reported lack of confidence in delivering the physical tasks (despite the fact that thorough and detailed instructions were included as part of the evaluation toolkit, as well as training was provided during Toolkit Training Days).

Despite these obstacles, the findings revealed some statistically significant changes preproject and post-project results.

Pre- and Post-Project Changes in Health Related Fitness Indicators

Results presented in Table 5 indicate that health related fitness markers significantly improved following the girls' involvement in the Programme. Even though results are based on a very small percentage of our whole sample size, these too suggest that short-term interventions can produce favourable improvements. For example, girls that took part in the 1-mile jog/run exercise improved significantly their mean average time from 13.11 minutes to 11.25 minutes between the beginning and end of their project, while those that took part in the sit-ups test increased their mean average number of sit-ups from 21.67 to 26.77 .

Although there were significant improvements in each of the indicators chosen for the evaluation, the average pre-project and post-project results fell below the healthy reference values for similar aged girls obtained from extensive physical fitness surveys in children, in America and Europe (see Barker et al, 2001; Committee for the Development of Sport (CDDS),1988). The average post-project time of 11.25 minutes for the 1 mile run/jog exercise was outside the healthy reference values of 8:30 - 11:00 minutes. Some girls did record results that were within the healthy reference values for some indicators, but the majority of girls' results were poor. 


\section{Insert Table 5}

The large SDs observed in the sit and reach test, as a marker of lower back and leg flexibility, indicates that a large proportion of girls actually achieved negative scores, suggesting that from the sitting position, these girls could not bend forwards beyond their knees. Such an astonishing observation could be attributed either to incorrect measurement reading, severe de-conditioning of the musculoskeletal system or high levels of obesity. It was not possible to assess whether obesity was a factor in the low flexibility scores. Although measurement of waist circumference was requested, none of the projects returned these data.

It should be noted that the reported scores are based on small sample sizes and therefore may not be an accurate or valid representation of girls at all the projects. It is possible that the girls who performed and returned the physical fitness profiles represent the most motivated and/or more physically confident young girls. Even with the more motivated girls, as is usually the case with self reported physical activity levels, overestimation of physical profile scores is possible, which highlights a serious problem in young girls' physical function status that is necessary for safely performing even the simplest activities of daily living.

While there were significant improvements in the scores of each indicator, it is not known whether the improvements represent actual physiological changes (e.g. fitter, stronger), or whether the improvements reflect the girls' greater willingness to try harder. There were indications from project organisers that the girls in many projects were much fitter, but also more willing to try new things and put in more effort. Regardless of the reasons for the changes, the findings indicate positive outcomes resulting from engagement in the projects. 


\section{DISCUSSION}

The key programme stakeholders expressed mixed responses to the findings on girls' participation in physical activity while engaged in the projects. The results of drop out and the low levels of MVPA accumulated by girls were considered disappointing, while the statistically significant changes in self-reported measures and the health related fitness indicators were received well.

There were expectations that girls would accumulate much more activity during a one hour session of activity, thus making a substantial contribution to the 60 minutes of moderate level activity recommended on a daily basis. However, two things should be considered when assessing the amount of MVPA that could be accumulated at the projects. Firstly, it should be remembered that many girls were very inactive at the time they joined the projects. It would be unreasonable to expect these girls to shift from having an inactive lifestyle to meeting recommended levels of activity over a short period of time. Secondly, while many forms of dance demand high energy expenditure when performed properly, this may not be the case when learning how to dance. The stop-start nature of learning how to dance (e.g. observing and copying the teacher) will limit the amount of activity that can be accumulated. It was evident from many projects that the girls were learning how to dance and the opportunity to be involved in continuous activity was limited, particularly at the beginning of projects.

It is also worth noting that the activities chosen for the accelerometer studies were those activities that were expected to record the highest levels of MVPA. Many projects included activities that would not be expected to result in high levels of MVPA (e.g. yoga, Pilates, skiing). The physical health benefits of taking part in these activities might be improved strength, balance, core stability or flexibility. 
The results on girls' self-reported measures of activity suggest a positive impact on girls' levels of activity between the beginning and end of projects. While these are positive and suggest that short-tem projects can influence engagement in activity, the results need to be treated with caution. Self-reported measures can often result in over-estimations of physical activity (Hagstromer, 2007). Furthermore, girls completing questionnaires may wish to show the projects in a favourable way which may lead them to provide favourable results. There is no evidence to suggest that the findings are not correct, but it is important to recognise the limitations of self-reported measures.

The changes in health related fitness measures present some evidence of the potentially positive impact of the projects on girls' fitness. Although the mean average post-project results were below healthy reference values, they still represented significant increase in performance. Even if the improvements are not a direct result of physiological changes in the girls (e.g. improved endurance, strength or flexibility), the changes demonstrate the girls' increased willingness to engage in challenging activities and put in more effort.

\section{Other Benefits}

Although this paper focussed on measures of girls' engagement in, and levels of, physical activity, the evaluation identified a number of other benefits of the Programme. These included psychological-well being, social and community benefits. For example, measures of physical self-description (self-esteem and self-efficacy) from beginning to the end of projects were found to be statistically significant, although it is difficult to determine to what extent this was directly attributable to the Programme. Furthermore, girls indicated (through selfreporting) that they had increased their enjoyment of taking part in activity, they were more confident in trying new activities, and that they would like to be more active. In social terms the girls indicated that the activities were important to developing their social networks, with four out of five claiming that they had developed new friendships as a result of taking part. 
Furthermore, the evaluation findings suggest that the Programme removed many of the barriers faced by girls who wish to engage in activities. In particular the 'girls only' aspect of the projects was exceptionally important to their involvement.

\section{Limitations of Evaluating Community-Based Physical Activity Interventions}

This study highlighted many of the problems associated with researching and evaluating community-based programmes. The problems encountered included self-selection bias, generalising findings from small sample sizes and evaluating programmes where the desired outcomes were vague, ambitious and wide ranging (Coalter, 2008). The overall aim of the programme sought increases in girls' participation in physical activity without specifying measurable targets. The applications for funding from the community groups listed outcomes that comprised many aspects of the social inclusion agenda (health, education, reduced crime, community cohesion) (Coalter, 2008). Furthermore, the organisers' and deliverers' appreciation of the mechanisms that are needed to achieve desired outcomes were simplistic. For many there was an automatic assumption that taking part in activity would lead to improved health. Little evidence was identified that showed that organisers and deliverers understood the importance of the frequency, duration and intensity of participation in physical activity needed to improve physical fitness that could then lead to improved health. With many of the organisers and deliverers coming from a youth work background, rather than a sport or physical education background, this may explain some stakeholders' lack of knowledge or understanding. Despite these difficulties, the evaluation raised some important findings about the impact of the programme on girls' physical activity.

\section{CONCLUSIONS}

The findings from the evaluation reinforce understanding about girls' participation in physical activity. Many girls in Scotland aged 11 and over are inactive and they are not active enough 
on a daily basis to accrue the health benefits afforded to those with a physically active lifestyle. The amount of MVPA accumulated by some girls in the organised physical activity sessions was worryingly low. Despite some of the findings, the evaluation of the 'Girls on the Move' Programme has demonstrated that short-term community-based physical activity projects (up to 6-months) designed by, and for, girls can make an important contribution to girls' becoming more physically active. The findings point to statistically significant increases in physical activity (albeit self-reported) that may be important in arresting the decline in the proportion of girls becoming inactive.

If community provision is to impact positively on the health of girls, steps should be taken to encourage girls to be more active during sessions. Organisers and deliverers should introduce into sessions activities that challenge the participants to increase intensity levels or ensure that there are longer periods during the sessions where movement is more prolonged, particularly in dance sessions. However, this needs to be undertaken in a sensitive way to ensure that it does not push the girls too far, thus contributing to drop out.

The findings demonstrate that a single session of activity is not enough to generate sufficient MVPA to reach daily recommended levels of 60 minutes of activity for children. While engagement in an activity class or group may appear outwardly as though its participants are being physically active, this alone will not provide the level of activity necessary to contribute to improved health. Even the most active girls at the projects need to be active at other times of the day (e.g. PE, active living) if they are to accumulate the time needed to reach the recommended 60 minutes per day of moderate level activity.

The 'Girls on the Move' Programme as a community-based programme is making an important contribution to challenging girls' to become more physical active. Importantly, it is responding to girls' demands for physical activity; however, if the Programme is to impact on national participation figures, many more opportunities are needed for girls across Scotland. 
Acknowledgements: The evaluation team would like to thank all the project organisers and girls for their contributions to the evaluation.

Details of the 'Girls on the Move' Programme can be obtained from the web at www.girlsonthemove.co.uk 


\section{REFERENCES}

Barker, A., Boreham, C., Van Praagh, E. and Rowlands, A.V. (2001) Chapter 8: Special consideration for assessing performance in young children. In, R. Eston and T. Reilly (eds) Kinanthropometry and exercise physiology laboratory manual: Test procedures and data, London, Routledge.

Coalter, F. (2007) A Wider Social Role for Sport: Who's Keeping the Score? Abingdon, Routledge.

Coalter, F., Allison, M. and Taylor, J. (2000) The Role of Sport in Regenerating Deprived Urban Areas, Edinburgh, Scottish Executive Central Research Unit.

Committee for the Development of Sport (CDDS) (1988) EUROFIT: European Test of Physical Fitness, Council of Europe, Committee for the Development of Sport (CDDS), Rome.

Dwyer, J.J.M., Allison, K.R., Goldberg, E.R., Fein, A.J., Yoshida, K.K. and Boutilier, M.A. (2006) Adolescent Girls' Perceived Barriers to Participation in Physical Activity, Adolescence, 41(161), 75-89.

EPPI (2001) Young People and Physical Activity: A Systematic Review of Research on Barriers and Facilitators, Social Science Research Unit, University of London.

Hagstromer, M., Oja, P. and Sjostrom, M. (2007) Physical Activity and Inactivity in an Adult Population Assessed by Accelerometry, Medicine and Science in Sports and Exercise, 39(9), 1502-1506. 
Hughes A.R., Henderson, A., Ortiz-Rodriguez, V., Artinou, M. and Reilly, J.J. (2006) Habitual Physical Activity and Sedentary Behaviour in a Clinical Sample of Obese Children. International Journal of Obesity, 30, 1494-1500.

Institute for Aerobics Research (1987) FITNESSGRAM Users Manual, Dallas, TX.

Nilsson, A., Ekelund, U., Yngve, A., and Sjöström, M. (2002) Assessing Physical Activity Among Children with Activity Monitors using Different Time Sampling Intervals and Placements, Pediatric Exercise Science, 14, 75-84.

Scottish Executive (2004) Analysis of Ethnicity in the 2001 Census, Edinburgh: Scottish Executive, Office of the Chief Statistician

http://www.scotland.gov.uk/Resource/Doc/47210/0025543.pdf

Scottish Executive (2003) Let's Make Scotland More Active: A Strategy for Physical Activity, Edinburgh, Scottish Executive

Sleap, M. and Wormald, H. (2001) 'Perceptions of Physical Activity among Young Women Aged 16 and 17 Years', European Journal of Physical Education, 6, 26-37.

Sport England (2002) Adults with a Disability and Sport Survey: National Survey 2000-2001 Main Report, London, Sport England.

sportscotland (2005) Making Women and Girls More Active: A Good Practice Guide, Edinburgh, sportscotland.

Vu, M., Murrie, D., Gonzalez, V. and Jobe, J. (2006) Listening to Girls and Boys Talk about Girls' Physical Activity Behaviors, Health Education and Behavior, 33(1), 81-96. 
Warburton, D.E.R., Nicol, C.W. and Bredin, S.D. (2006) Health Benefits of Physical Activity: The Evidence, CMAJ, 174(6), 801-809.

Wheeler, D.W., Whittlestone, K.D., Johnston, A.J. and Smith H.L. (2006) Problems Encountered with a Pilot Online Attendance Record and Feedback Scheme for Medical Students, Education for Health, 19(3), 369-374. 


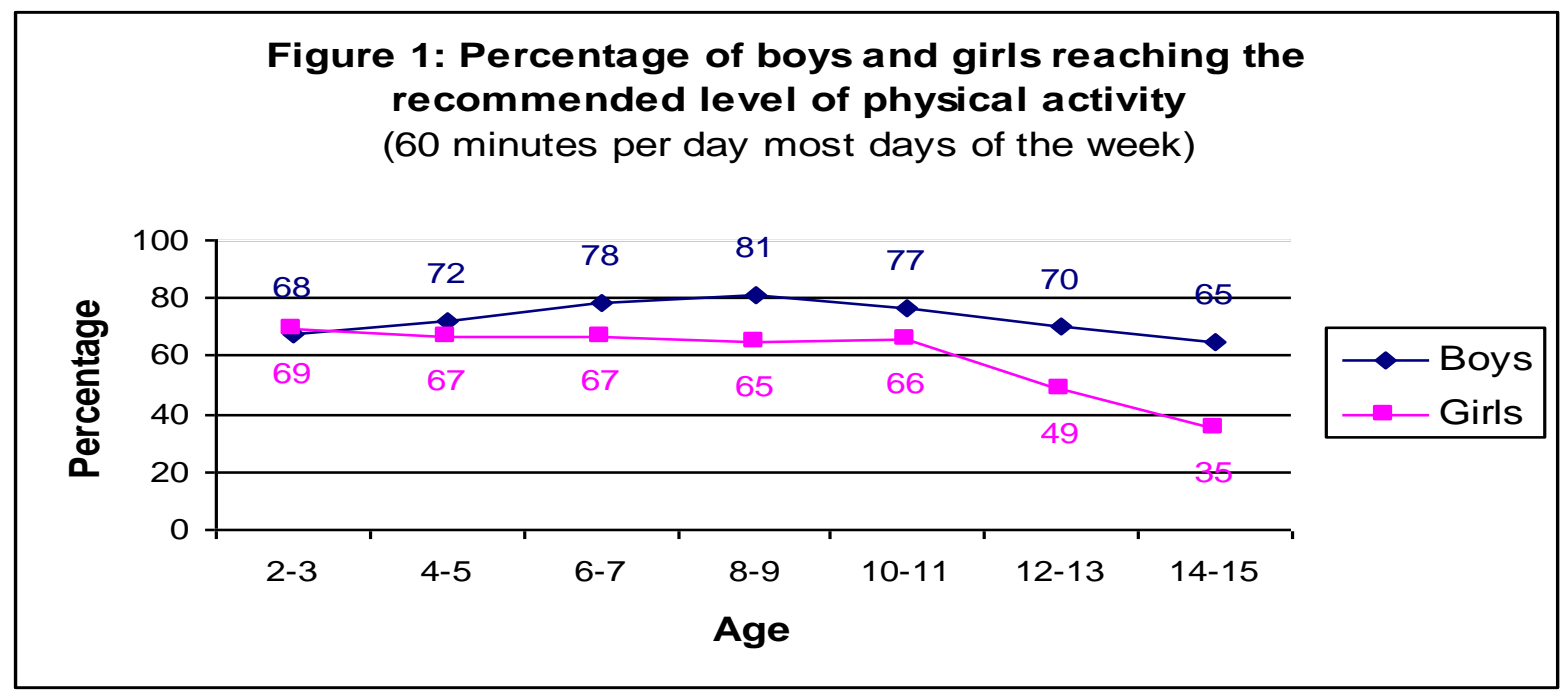

Source: Scottish Executive (2003), findings from the Scottish Health Survey 1998

Figure 2: Example attendance sheet

\begin{tabular}{|c|c|c|c|c|c|c|c|c|c|c|c|c|c|c|c|}
\hline $\begin{array}{l}\text { Name of } \\
\text { participant }\end{array}$ & 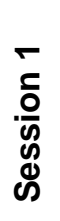 & 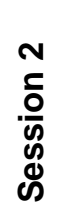 & 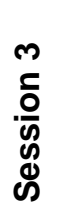 & 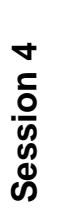 & 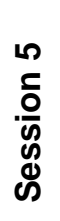 & 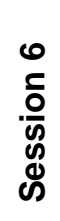 & 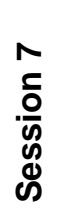 & 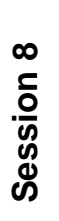 & 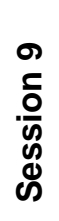 & 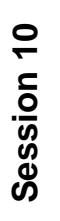 & 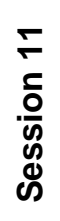 & 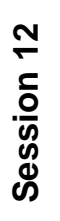 & 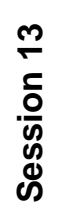 & 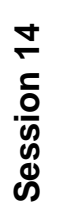 & 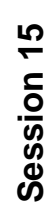 \\
\hline Christine S & $\checkmark$ & $\checkmark$ & $\checkmark$ & - & - & $\checkmark$ & $\checkmark$ & $\checkmark$ & $\checkmark$ & $\checkmark$ & $\checkmark$ & $\checkmark$ & $\checkmark$ & $\checkmark$ & $\checkmark$ \\
\hline Mary A & - & - & - & - & - & $\checkmark$ & $\checkmark$ & $\checkmark$ & - & - & - & - & - & - & - \\
\hline etc & & & & & & & & & & & & & & & \\
\hline & & & & & & & & & & & & & & & \\
\hline
\end{tabular}

Table 1: Attendance at 'Girls on the Move' Projects

\begin{tabular}{lrrrrr}
\hline & Minimum & Maximum & Total & $\begin{array}{c}\text { Mean } \\
\text { average }\end{array}$ & Std Dev \\
\hline Number of sessions delivered & 4 & 63 & 1,219 & 18 & 12.7 \\
Number of places available & 5 & 200 & 1,470 & 21 & 24.6 \\
Total possible throughput & 45 & 1,258 & 18,462 & 272 & 240.3 \\
Number of girls that attended & 5 & 171 & 1,470 & 21 & 23.0 \\
Total throughput achieved & 39 & 844 & 12,173 & 176 & 168.9 \\
Attendance rate (\%) - based on & & & $66 \%$ & & \\
possible throughput & & & & & \\
\hline
\end{tabular}

Notes: The figures are based on attendance at 69 projects. 
Table 2: Level of attendance at 'Girls on the Move' Projects

\begin{tabular}{lllc}
\hline & & Number & Percentage \\
\hline High & - girls that attended more than $75 \%$ of sessions & 585 & 40 \\
Moderate & - girls that attended $51-75 \%$ of sessions & 334 & 23 \\
Low & - girls that attended $26-50 \%$ of sessions & 238 & 16 \\
Very low & - girls that attended $25 \%$ or fewer sessions & 299 & 21 \\
\hline \multicolumn{2}{l}{ Base number } & \multicolumn{2}{c}{1,456} \\
\hline
\end{tabular}

Table 3: Mean average and percentage of time spent in physical activity

\begin{tabular}{lcc}
\hline & $\begin{array}{c}\text { Mean average minutes } \\
\text { per hour of activity }\end{array}$ & Percentage \\
\hline Moderate/Vigorous Physical Activity (MVPA) & 10 & 17 \\
Light activity & 17 & 28 \\
Sedentary & 33 & 55 \\
\hline
\end{tabular}

Note: Findings based on accelerometer counts obtained from 77 girls at 13 projects

Table 4: Pre-project and post-project PA levels in girls aged 12 and over - based on IPAQ questionnaire returns

\begin{tabular}{ll}
$\begin{array}{l}\text { Pre-project } \\
(\text { mean } \pm \text { SD) }\end{array}$ & $\begin{array}{l}\text { Post-project } \\
(\text { mean } \pm \text { SD) }\end{array}$ \\
\hline
\end{tabular}

\section{Number of days per week}

Number of days girls did vigorous intensity exercise in the 7 days before the survey $(n=88)$

$\begin{array}{ll}1.73 \pm 1.58 & 2.48 \pm 1.76 \\ 1.65 \pm 1.77 & 3.07 \pm 2.02\end{array}$

Number of days girls did moderate intensity exercise in the 7 days before the survey $(n=88)$ $($ mean \pm SD (mean \pm SD)

\section{Number of minutes per day}

Number of minutes per day spent in vigorous intensity exercise $(n=88)$

$52.10 \pm 53.35 \quad 68.90 \pm 51.38$

Number of minutes per day spent in moderate intensity exercise $(n=88)$

\section{Walking}

Number of days where girls walked for at least 10 minutes in the 7 days before the survey $(n=88)$

Number of minutes per day spent walking in the7 days before the survey $(n=88)$

\section{Sitting}

Number of minutes spent sitting on a week day $(\mathrm{n}=42)$

Note: ${ }^{-S i g n i f i c a n t l y ~ d i f f e r e n t ~ c o m p a r e d ~ t o ~ p r e-p r o j e c t ~ s u r v e y, ~} p<0.05$ 
Table 5: Pre-project and post-project health related fitness indicator scores in girls aged 12 and over

\begin{tabular}{lccc}
\hline & $\begin{array}{c}\text { Pre-project } \\
\text { (mean } \pm \text { SD) }\end{array}$ & $\begin{array}{c}\text { Post-project } \\
\text { (mean } \pm \text { SD) }\end{array}$ & $\begin{array}{c}\text { Healthy Reference } \\
\text { Values* }\end{array}$ \\
\hline 1-mile jog/run (min) $(\mathrm{n}=21)$ & $13.11 \pm 3.52$ & $11.25 \pm 2.68$ & $8: 30-11: 00$ \\
Sit-ups (no, in 1 min) $(\mathrm{n}=44)$ & $21.67 \pm 6.87$ & $26.77 \pm 7.43$ & $30-40$ \\
Sit and Reach (cm) $(\mathrm{n}=33)$ & $0.43 \pm 13.37$ & $1.36 \pm 8.11$ & $+20-+26$ \\
STS-60 (no, in 1 min) $(\mathrm{n}=31)$ & $27.35 \pm 14.25$ & $34.35 \pm 15.96$ & $\begin{array}{c}\text { No reference values } \\
\text { for this population }\end{array}$ \\
Modified push ups & No data & No data & $10-16$ \\
\hline $\begin{array}{l}\text { Notes: *Adapted from FITNESSGRAM and EUROFIT healthy reference values for same age ranges. } \\
\text { These data are for those participants that provided both pre-project and post-project data. }\end{array}$
\end{tabular}

